\title{
Desinfecção sequencial: estudo de caso em ETE em escala plena
}

Efluentes domésticos, dependendo do processo de tratamento empregado, ainda possuem elevadas concentrações de micro-organismos patogênicos. Desta forma, a etapa de desinfeç̧ão é importantíssima no intuito de diminuição de riscos à saúde pública. Este trabalho teve o objetivo de investigar a adição de uma etapa de cloração, anteriormente à desinfecção com radiação ultravioleta, na inativação de cistos de Giárdia spp., oocistos de Cryptosporidium spp. e microrganismos indicadores - E. coli, coliformes totais e Clostridium perfringens - em uma ETE em escala plena. Foi observada a presença de cistos de Giárdia em todas as amostras de esgoto desinfetado. Os (oo)cistos de Giárdia e Cryptosporidium se mantiveram viáveis, $70 \pm 15,1 \%$ e $59 \pm 12 \%$, respectivamente, após o maior CT aplicado durante a cloração. A bactéria Clostridium perfringens, da mesma forma que os (oo)cistos de protozoários, provou ser bastante resistente à cloração em comparação aos coliformes totais e E. coli. Esta mesma relação de resistência também foi constatada para a radiação ultravioleta. Houve efeito sinérgico para E. coli, Clostridium perfringens e Giárdia spp. em dois ensaios de desinfecção sequencial. Somente após a aplicação da dose de 8 mg.L-1 de cloro em sequência à radiação UV, a meta microbiológica de projeto da ETE, para E. coli, foi atingida: $10^{3}$ UFC por $100 \mathrm{~mL}$.

Palavras-chave: Cloração; Radiação Ultravioleta; Sinergismo; Desinfecção.

\section{Sequential Disinfection: case study of full-scale WWTP}

Domestic wastewater, depending on the treatment process applied, may still have high concentrations of pathogenic microorganisms. Thus, the disinfection step is importante in order to decrease risks to public health. This research aimed to investigate the addition of a chlorination step prior to disinfection with ultraviolet irradiation, in the inactivation of Giardia spp. cysts, Cryptosporidium spp. oocysts and indicator organisms - E. coli, total coliforms and Clostridium perfringens - in a full-scale WWTP. The presence of Giardia cysts was observed in all samples of disinfected wastewater. The (oo)cysts of Giardia and Cryptosporidium remaid viable, $70 \pm 15.1 \%$ and $59 \pm 12 \%$, respectively, after the highest CT applied during chlorination. The bacterium Clostridium perfringens, like protozoan (oo)cysts, proved to be quite resistant to chlorination compared to total coliforms and E. coli. This same relation of efficiencies was also verified for ultravioleta irradiation. Synergistic effects were found for E. coli, Clostridium perfringens and Giardia spp. in two sequential disinfection trials. Only after application of 8 mg.L-1 of chlorine in sequence to UV irradiation, the microbiological design goal of the WWTP for E. coli was reached: $10^{3} \mathrm{CFU}$ per $100 \mathrm{~mL}$.

Keywords: Chlorination; Disinfection; Sinergism; UV Irradiation.

Topic: Engenharia Sanitária

Reviewed anonymously in the process of blind peer
Received: 10/02/2018

Approved: 24/03/2018
Raphael Corrêa Medeiros (iD

Universidade Federal de Santa Maria, Brasil

http://lattes.cnpq.br/2977594460581447

http://orcid.org/0000-0002-7090-1731

medeiroscg@yahoo.com.br

Luci Sartori

Universidade de Araraquara, Brasil

http://lattes.cnpq.br/7855962454430004

lucisartori.sartori@gmail.com

\section{Luiz Antonio Daniel (iD)}

Universidade de São Paulo, Brasil

http://lattes.cnpq.br/1620570536303906

http://orcid.org/0000-0002-1765-4209

Idaniel@sc.usp.br

\section{Referencing this:}

MEDEIROS, R. C.; SARTORI, L.; DANIEL, L. A.. Desinfecção sequencial: estudo de caso em ETE em escala plena. Revista Ibero Americana de Ciências Ambientais, v.9, n.3, p.149-160, 2018. DOI: http://doi.org/10.6008/CBPC2179-6858.2018.003.0013 


\section{INTRODUÇÃO}

A gestão de recursos hídricos precisa ser estendida até o lançamento de esgotos tratados e desinfetados, pois quando lançados nos corpos d'água e/ou reutilizados, podem representar riscos à saúde pública (WANG et al., 2012). A desinfecção é a inativação de microrganismos capazes de causar doenças a um nível que não seja mais significante à saúde pública. A desinfecção de água para abastecimento público é provavelmente a medida de prevenção de doenças mais significativa na história humana (BITTON, 2011).

O tratamento convencional de águas residuárias, na ausência de desinfecção, não fornece remoção e inativação de patógenos com eficiência compatível ao padrão microbiológico de água para reúso e contato público. Desse modo, a desinfecção promoveria: proteção da saúde, ao servir de barreira contra organismos patogênicos; redução do risco de transmissão de doenças; além de objetivar e garantir reúso da água (BITTON, 2011; WANG et al., 2012; Ll et al., 2017a).

Efluentes domésticos, dependendo do processo de tratamento empregado, ainda possuem elevadas concentrações de cistos de Giárdia spp. e oocistos de Cryptosporidium spp. Esses protozoários são caracterizados por apresentarem: baixa dose infectante, resistentes em ambientes desfavoráveis, eliminados em grandes concentrações por indivíduos doentes e assintomáticos (ADAM, 2001; CAREY et al., 2004). Em esgoto bruto, são encontrados normalmente de $10^{2}$ a $10^{5}$ (oo)cistos por litro (CANTUSIO NETO et al., 2006; TONANI et al., 2013). Em efluentes após o tratamento secundário, como os lodos ativados, são reportadas concentrações acima de $10^{2}$ (oo)cistos por litro (CASTRO-HERMIDA et al., 2008; MOULIN et al., 2010; TONANI et al., 2013).

Os derivados do cloro são os desinfetantes mais utilizados no mundo para tratamento de água de abastecimento e águas residuárias. Após o processo de hidrólise, formam ácido hipocloroso ( $\mathrm{HOCl})$, que age, principalmente, na membrana plasmática da célula, modificando sua permeabilidade, promovendo a precipitação de proteínas, hidrólise e ruptura da célula; pode também provocar danos aos ácidos nucleicos (BITTON, 2011; WANG et al., 2012).

Os derivados de cloro, em grande parte, são muito seletivos para compostos orgânicos e sua reatividade é limitada a sítios específicos da molécula orgânica, como grupamentos amina, com consequente formação de cloraminas (DEBORDE et al., 2008). Encontrar o equilíbrio entre a eficiência da desinfecção e a formação dos subprodutos da desinfeç̧ão vem sendo o foco de extensas investigações de processos alternativos de desinfecção (NADDEO et al., 2009; PARK et al., 2016).

Com os riscos envolvidos na estocagem do cloro gasoso e as preocupações com subprodutos da desinfecção do cloro, a partir da descoberta dos trihalometanos na década de 70 , segundo Sedlak et al. (2011), o uso do cloro na desinfecção em ETAs e ETEs vem, aos poucos, sendo desencorajado. Porém, segundo os mesmos autores, com a mudança para outros desinfetantes, podem-se perder efeitos benéficos da cloração, principalmente na transformação de compostos desruptores endócrinos e o controle do crescimento microbiano em redes de distribuição de água tratada. 
Como alternativa à cloração, e baseada na alteração do DNA e RNA dos micro-organismos, a radiação ultravioleta mostra inúmeras vantagens, entre elas: não deixa residual no efluente tratado e sua eficácia não é afetada pelo pH ou temperatura (HIJNEN et al., 2006). No entanto, é afetada pela qualidade do efluente, principalmente, turbidez, tamanho e concentração de sólidos suspensos e cor (JIN et al., 2013; ZHOU et al., 2017).

A luz UV é a porção do espectro eletromagnético localizada entre a luz visível e os raios $\mathrm{X}$. Sua atividade germicida é devida à radiação emitida, próxima ao comprimento de onda de $260 \mathrm{~nm}$, ser de grande absorção pelo DNA celular, causando dimerização das bases nitrogenadas timina e citosina e consequente bloqueio da replicação e transcrição do DNA (BITTON, 2011; EINARSSOM et al., 2015).

De acordo com Li et al. (2017b), a desinfecção sequencial se insere na busca pelo desenvolvimento e otimização do processo de desinfecção. Ela se constitui na aplicação de dois ou mais desinfetantes em sequência, onde a ação combinada pode promover maior inativação de micro-organismos que a soma das inativações dos mesmos desinfetantes aplicados separadamente, que é chamado sinergismo (FINCH et al., 2000). Com isso, pode-se evitar aumentar a dose, ou o tempo de contato dos desinfetantes, e consequentemente, menores custos e/ou formação de subprodutos (LI et al., 2017a).

Alguns estudos, em pequena escala, relatam a capacidade de a desinfecção sequencial inativar: bactérias (WANG et al., 2011, 2012; LI et al., 2017ab), vírus resistentes (BALLESTER et al., 2004), genes resistentes a antibióticos (ZHANG et al., 2015), protozoários (MONTEMAYOR et al., 2008; MEDEIROS et al., 2015a). Desta forma, este trabalho teve o intuito de investigar as melhores doses de hipoclorito de sódio, em escala de bancada, para a inativação de micro-organismos indicadores e protozoários patogênicos, a fim de adicionar a etapa de cloração previamente à radiação ultravioleta em uma ETE em escala plena.

\section{METODOLOGIA}

\section{A ETE Monjolinho}

A ETE Monjolinho trata $100 \%$ da água residuária coletada na cidade de São Carlos - SP, vazão de

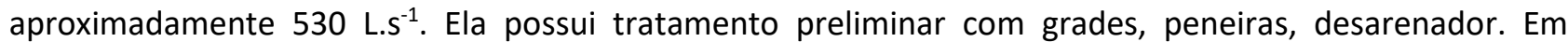
seguida, o esgoto segue para reatores anaeróbios do tipo UASB, com tempo de detenção hidráulica (TDH) de 6 a 8 horas, e, posteriormente, é encaminhado para Flotadores de Ar Dissolvido.

Antes do lançamento final no corpo receptor, há a unidade de desinfecção por radiação ultravioleta, composta por 480 lâmpadas monocromáticas (emissão de radiação próxima a $254 \mathrm{~nm}$ ) distribuídas em dois canais paralelos. Cada canal é composto por dois módulos de lâmpadas, as quais estão envoltas por tubo de quartzo e permanecem imersas no meio líquido. $O$ tempo de detenção hidráulica, quando em vazão média, é de 9,1 segundos; e, em vazão máxima, 4,0 segundos. A dose de radiação ultravioleta aplicada por volume é próxima a $10 \mathrm{Wh} \cdot \mathrm{m}^{-3}$.

Devido à elevada concentração de $E$. coli no efluente das unidades de flotação, a radiação ultravioleta não conseguia atingir a eficiência necessária para o efluente desinfetado obter qualidade microbiológica 
exigida pelo órgão ambiental e ser lançado no corpo receptor. Em razão disso, foram realizados estudos de cloração, em escala de bancada, como alternativa de desinfetante a ser utilizado previamente à desinfecção por ultravioleta.

Dessa forma, o trabalho pode ser dividido em três etapas: I - verificação da eficiência de inativação da unidade de desinfecção por radiação ultravioleta; II - ensaios em bancada de desinfecção com cloro, para escolha da melhor dosagem; III - aplicação in situ da cloração e verificação da eficiência da desinfecção sequencial e a ocorrência de efeito sinérgico.

\section{Etapa I - Desinfecção por radiação ultravioleta na ETE Monjolinho}

Nesta etapa, foram coletadas amostras antes e após a unidade de desinfecção, em frascos de 1 litro de capacidade, previamente lavados, desinfetados e enxaguados com solução Tween 80 (0,1\%).

\section{Etapa II - Ensaios em bancada de desinfecção com cloro}

Foram realizados quatro ensaios de cloração do efluente proveniente das unidades de flotação. 0 efluente foi coletado em galões de 20 litros, previamente lavados, desinfetados e enxaguados com solução Tween $80(0,1 \%)$. Os ensaios foram feitos em batelada, em unidade de bancada, no Laboratório de Tratamento Avançado e Reuso de Águas (LATAR), na USP - São Carlos. Para isso, béqueres de vidro com dois litros de capacidade, desinfetados e enxaguados com solução Tween $80(0,1 \%)$, foram preenchidos com 1,5 litros de efluente e colocados em aparelho jar-test com ajuste de gradiente de velocidade de $100 \mathrm{~s}^{-1}$.

Neste caso, foram aplicadas as seguintes concentrações de cloro: 2,$5 ; 7,5 ; 15$ e $30 \mathrm{mg} \cdot \mathrm{L}^{-1}$. O tempo de contato foi fixo em oito minutos, pois equivale ao tempo necessário para o efluente percorrer desde a saída dos flotadores até a entrada na unidade de desinfecção por radiação ultravioleta. Houve o intuito de realizar o mínimo de medida estrutural possível para a cloração. Com isso, foram analisados os seguintes valores de concentração x tempo (CTs): 20, 60, 120 e $240 \mathrm{mg} \cdot \mathrm{min} \cdot \mathrm{L}^{-1}$, respectivamente.

A solução de hipoclorito de sódio utilizada foi preparada no dia dos ensaios, a partir de solução estoque com concentração de 4 a 6\% (Vetec Química Fina ${ }^{\circledR}$, Ltda). A análise de cloro residual total e livre foi conduzida pelo método DPD (N, N-diethyl-p-phenylenediamine) colorimétrico utilizando espectrofotômetro (DR 2010, $\mathrm{Hach}^{\circledR}$ ). No final dos testes, foi utilizada solução de metabissulfito de sódio $\left(\mathrm{Na}_{2} \mathrm{~S}_{2} \mathrm{O}_{5}\right)$ a $3 \%$, na proporção de 0,1 mL para cada $100 \mathrm{~mL}$ de amostra, a fim de remover cloro residual livre e combinado ainda presentes, e se proceder aos exames microbiológicos. Em decorrência dos resultados desses ensaios em bancada, foram escolhidas as melhores dosagens para aplicação na ETE Monjolinho.

\section{Etapa III - Desinfecção sequencial in situ}

A partir dos resultados obtidos pelos ensaios de cloração em bancada, foi idealizada uma calha para distribuição de solução de hipoclorito de sódio, no canal de saída do efluente dos flotadores. Foram realizadas três amostragens de desinfecção sequencial, sendo coletadas amostras em três pontos distintos: antes da cloração (efluentes dos flotadores); após a cloração e, portanto, antes da desinfecção com radiação 
UV; e após cloração e radiação UV (desinfecção sequencial). O cálculo de efeito sinérgico para desinfecção individual por UV, proposto por Finch et al. (2000), foi efetuado pela equação 1:

Sinergismo = Inativação sequencial observada $-(\Sigma$ Inativações individuais $)$

\section{Análises Físico-Químicas}

As análises físico-químicas de: absorbância em $254 \mathrm{~nm}, \mathrm{DQO}, \mathrm{pH}$, sólidos totais, sólidos suspensos totais e turbidez, utilizadas para caracterizar e monitorar os ensaios de desinfecção, seguiram o Standard Methods for the Examination of Water and Wastewater (APHA et al., 2005).

\section{Exames Microbiológicos}

\section{Escherichia coli e coliformes totais}

Para a quantificação de $E$. coli e coliformes totais foi realizada pela técnica membrana filtrante, com a utilização do meio Chromocult ${ }^{\circledR}$ Coliform Agar (Merk ${ }^{\circledR}$ Cat.No.1.10426), conforme descrito em Medeiros et al. (2015a).

\section{Clostridium perfringens}

A técnica de membrana filtrante foi utilizada para quantificar esporos de Clostridium perfringens, de acordo com o método L5.403 (CETESB, 2004). De forma geral, são três passos principais, especificados em Medeiros et al. (2015a): filtração em membrana estéril de nitrato de celulose com 0,45 $\mu \mathrm{m}$ de porosidade (Sartorius ${ }^{\circledR}$ Stedim Biotech GmbH, Germany) e inoculação em meio de cultura seletivo e diferencial Água mCP (Oxoid ${ }^{\circledR}$ Ltda, England), seguida de verificação das colônias após contato com vapores de hidróxido de amônio; primeira confirmação das colônias, em meio Tioglicolato (CM 0173, Oxoid ${ }^{\circledast}$ Ltda, England); segunda confirmação das colônias, em meio de leite com ferro modificado.

\section{Giardia spp. e Cryptosporidium spp.}

Na análise de cistos de Giárdia e oocistos de Cryptosporidium, foi empregado o método da filtração em membrana de ésteres mistos de celulose com porosidade de $3 \mu \mathrm{m}$ ( $47 \mathrm{~mm}$ de diâmetro, Millipore ${ }^{\circledR}$ ), conforme descrito em Medeiros et al. (2015b). Este método, segundo os mesmos autores, apresenta porcentagens de recuperação de: 67,5\% para cistos de Giárdia e 22,5\% para oocistos de Cryptosporidium; portanto, dentro dos valores requeridos pelo método 1623 (USEPA, 2012).

A baixa recuperação de oocistos de Cryptosporidium pode estar relacionada, de acordo com Santos et al. (2017), à flexibilidade dos oocistos, ao seu aprisionamento na membrana filtrante, e ao grande número de partículas presentes que influenciam no processo de eluição. Depois da etapa inicial de concentração da amostra, foi utilizada a Reação por imunofluorescência direta (RID), com o kit Merifluor ${ }^{\circledR}$ e acréscimo de corante DAPI, utilizado para confirmação dos (oo)cistos. 
A viabilidade dos cistos e oocistos foi inferida através da coloração diferencial com iodeto de propídeo (Sigma-Aldrich ${ }^{\circledR}$, USA), de acordo com Campbell et al. (1992). Esse reagente, responsável pela emissão de fluorescência vermelha $(\lambda=510$ a $550 \mathrm{~nm})$, penetra apenas nos microrganismos com membrana danificada (células mortas). Cistos e oocistos sem penetração do corante (PI-) foram considerados viáveis, e os que apresentaram penetração do corante $(\mathrm{PI}+)$, inviáveis. As amostras foram examinadas em microscópio de imunofluorescência (Olympus ${ }^{\circledR}$ BX51) sob aumento de 400X a 800X. Para o cálculo da concentração de (oo)cistos por litro, foi utilizada a equação 2 (CANTUSIO NETO et al., 2006):

$$
\text { (oo)cistos } / L=\frac{n^{\mathrm{o}}(\mathrm{oo}) \text { cisto detectado } \times 10^{6} \times \text { volume total de sedimento }(\mathrm{mL})}{\text { volume de sedimento na lâmina }(\mu L) \times \text { volume da amostra }(\mathrm{mL})}
$$

\section{Análise Estatística}

A eficiência da desinfecção foi expressa como log (No/N), onde No e $\mathrm{N}$ representam o número de micro-organismos na amostra antes e após a desinfecção, respectivamente. A relação linear entre a redução $(\log )$ e a dose aplicada de desinfetante pode ser utilizada para descrever o modelo de desinfecção. Neste caso, foi utilizada a formulação do modelo linear de 1a ordem de Chick-Watson, apresentado como: log $(\mathrm{No} / \mathrm{N})=\mathrm{k} * \mathrm{CT}$, onde $\mathrm{k}$ representa a constante de inativação e o CT (concentração x tempo de contato), para os ensaios de cloração em bancada. Nas comparações, foi utilizado o teste t. Para valores de $p<0,05$, a diferença foi considerada significativa.

\section{RESULTADOS E DISCUSSÃO}

\section{Etapa I}

As características físico-químicas e microbiológicas da água residuária afluente à unidade de desinfecção podem ser visualizadas na tabela 1. As médias geométricas dos (oo)cistos de protozoários foram mais elevadas em relação ao trabalho de Moulin et al. (2010), Tonani et al. (2013) e de Santos et al. (2017); no entanto, próximas às de Chávez et al. (2011), para esgoto tratado secundariamente. Cistos de Giárdia e oocistos de Cryptosporidium apresentaram viabilidades médias de $78( \pm 7,5)$ e $87,5( \pm 25) \%$, respectivamente.

Tabela 1: Qualidade física, química e microbiológica do esgoto após etapa de flotação da ETE - Monjolinho.

\begin{tabular}{|c|c|c|c|}
\hline Variáveis & $\mathbf{n}$ & Média \pm DP & Intervalo \\
\hline pH & 4 & $7,16 \pm 0,05$ & $7,09-7,21$ \\
\hline Turbidez (UNT) & 4 & $40,40 \pm 20,54$ & $22,4-64,9$ \\
\hline Absorbância 254 nm & 4 & $0,337 \pm 0,045$ & $0,295-0,381$ \\
\hline DQO (mg. $\left.\mathrm{L}^{-1}\right)$ & 4 & $135 \pm 58$ & $86-218$ \\
\hline Sólidos Totais (mg. $\mathrm{L}^{-1}$ ) & 4 & $476 \pm 57$ & $397-538$ \\
\hline Sólidos Suspensos Totais (mg. $\left.\mathrm{L}^{-1}\right)$ & 4 & $49 \pm 17$ & $28-67$ \\
\hline Coliformes totais (UFC/100 mL)* & 8 & $2,2 \times 10^{6}$ & $9,0 \times 10^{4}-4,4 \times 10^{6}$ \\
\hline Escherichia coli (UFC/100 mL)* & 8 & $3,6 \times 10^{5}$ & $3,0 \times 10^{4}-1,7 \times 10^{6}$ \\
\hline Clostridium perfringens (UFC/100 mL)* & 8 & $2,3 \times 10^{4}$ & $7 \times 10^{3}-4,5 \times 10^{4}$ \\
\hline Giardia spp. (cistos/L)* & 5 & $1,1 \times 10^{3}$ & $5 \times 10^{2}-2,7 \times 10^{4}$ \\
\hline Cryptosporidium spp. (oocistos/L)* & 5 & $6,2 \times 10^{1}$ & $\mathrm{nd}-1,3 \times 10^{2}$ \\
\hline
\end{tabular}

Nota: $\mathrm{n}$ : número de amostras coletadas; DP: desvio padrão; UNT: unidade nefelométrica de turbidez; Abs $254 \mathrm{~nm}$ : absorbância em $1,0 \mathrm{~cm}$ de caminho óptico; UFC: unidades formadoras de colônia; nd: não detectado; *: Média geométrica. 
Santos et al. (2017), na mesma ETE, das amostras de esgoto provenientes da etapa de flotação, encontraram positividade de $100 \%$ para Giárdia e 25\% para Cryptosporidium. No presente trabalho, cistos de Giárdia e oocistos de Cryptosporidium foram encontrados em 100\% (5/5) e 60\% (3/5), respectivamente. Com relação aos micro-organismos indicadores, Santos et al. (2017) citam a dificuldade de removê-los pelo processo de flotação por ar dissolvido, talvez pela não adesão eficiente aos flocos ou bolhas de ar, provavelmente devido a alguma característica biológica na superfície dessas bactérias. Cabe destaque, portanto, à concentração de E. coli, padrão microbiológico de interesse. Os resultados obtidos da desinfecção com radiação ultravioleta estão expostos na tabela 2 , os quais se mostraram dependentes da limpeza realizada nas lâmpadas.

Tabela 2: Inativação de microrganismos por radiação UV na ETE Monjolinho.

\begin{tabular}{|l|l|l|l|}
\hline Micro-organismos & $\mathbf{N}$ & Inativação [-log (N/No)] & Intervalo \\
\hline Coliformes totais & 8 & $1,37 \pm 0,83$ & $0,11-2,18$ \\
\hline Escherichia coli & 8 & $1,43 \pm 0,71$ & $0,30-2,10$ \\
\hline Clostridium perfringens & 8 & $0,20 \pm 0,31$ & $0,0-0,94$ \\
\hline Giardia spp. & 5 & $0,47 \pm 0,50$ & $0,0-1,03$ \\
\hline Cryptosporidium spp. & 5 & $\mathrm{Nd}$ & nd \\
\hline
\end{tabular}

Nota: $\mathrm{n}$ : número de amostras; N: concentração final de micro-organismos; No: concentração inicial de micro-organismos; nd: não detectado.

Os microrganismos E. coli e coliformes totais foram mais facilmente inativados pela radiação UV ao comparar com Clostridium perfringens, resultados próximos aos de Sanctis et al. (2016), e à redução do número de cistos de Giárdia. Elevados valores de turbidez, DQO e concentração de substâncias que absorvem e espalham a radiação UV podem ter promovido a diminuição na eficiência da desinfecção (JIN et al., 2013; ZHOU et al., 2017).

Foi observada a presença de cistos de Giárdia em todas as amostras de esgoto desinfetado. No entanto, com diminuição da viabilidade para $41 \%$ ( \pm 16 ), porém sem diferença significativa quanto à viabilidade do esgoto não desinfetado $(p>0,05)$. Oocistos de Cryptosporidium não foram detectados após a desinfecção, sendo difícil a discussão sobre a diminuição de sua viabilidade.

Apesar de a unidade de desinfecção por radiação UV promover redução de até duas unidades logarítmicas de coliformes totais e $E$. coli, ainda não era suficiente para alcançar a qualidade microbiológica de projeto da ETE e solicitada pelo órgão ambiental: $10^{3}$ UFC por $100 \mathrm{~mL}$. Deve-se salientar que a falta de manutenção da unidade de desinfecção (limpeza e troca de lâmpadas) foi extremamente prejudicial, com diminuição significativa do poder de inativação das lâmpadas germicidas. Dessa maneira, idealizou-se a cloração previamente à desinfecção por radiação UV.

\section{Etapa II}

A qualidade físico-química do esgoto, após cloração em reator de bancada, está relatada na tabela 3. Pode-se perceber um incremento de $\mathrm{pH}$, devido à própria reação do hipoclorito de sódio gerando íons hidroxila $\left(\mathrm{OH}^{-}\right)$, durante a cloração. Outra variável a ser destacada são os sólidos totais, principalmente a 
parte relacionada aos sólidos dissolvidos, que podem tem aumentado de concentração em razão do acréscimo de metabissulfito de sódio para remoção de cloro residual (MEDEIROS et al., 2017).

Tabela 3: Qualidade física e química do esgoto, proveniente da flotação, após cloração (média \pm desvio padrão).

\begin{tabular}{|c|c|c|c|c|}
\hline & \multicolumn{4}{|c|}{ CT (concentração $x$ tempo de contato) mg.min. $\mathrm{L}^{-1}$} \\
\hline Variáveis & 20 & 60 & 120 & 240 \\
\hline pH & $7,35 \pm 0,04$ & $7,61 \pm 0,07$ & $8,07 \pm 0,10$ & $8,71 \pm 0,14$ \\
\hline Turbidez (UNT) & $28,3 \pm 8,3$ & $28,9 \pm 10,0$ & $33 \pm 7,5$ & $39,4 \pm 14,5$ \\
\hline Abs. $254 \mathrm{~nm}$ & $0,338 \pm 0,042$ & $0,335 \pm 0,044$ & $0,340 \pm 0,040$ & $0,372 \pm 0,052$ \\
\hline DQO (mg. L-1) & $153 \pm 74$ & $146 \pm 76$ & $144 \pm 62$ & $133 \pm 53$ \\
\hline ST (mg.L-1) & $585 \pm 63$ & $647 \pm 76$ & $807 \pm 157$ & $1199 \pm 76$ \\
\hline SST (mg.L-1) & $53 \pm 19$ & $48 \pm 18$ & $50 \pm 15$ & $51 \pm 19$ \\
\hline CRL (mg.t-1) & 0,0 & $0,28 \pm 0,32$ & $1,39 \pm 0,99$ & $5,30 \pm 1,12$ \\
\hline CRT (mg. L $\left.^{-1}\right)$ & 0,0 & $1,32 \pm 1,41$ & $4,64 \pm 2,41$ & $10,36 \pm 3,54$ \\
\hline Variáveis & 20 & 60 & 120 & 240 \\
\hline
\end{tabular}

Nota: UNT: unidade nefelométrica de turbidez; Abs $254 \mathrm{~nm}$ : absorbância em 1,0 cm de caminho óptico; ST: sólidos totais; SST: sólidos suspensos totais; CRL; cloro residual livre; CRT: cloro residual total.

Foram observadas, com o aumento da dose de cloro, maiores concentrações de cloro residual livre e total, com influência direta na sobrevivência de micro-organismos, cujos resultados de inativação estão mostrados na figura 1. A bactéria formadora de esporo - Clostridium perfringens - provou ser bastante resistente à cloração em comparação a coliformes totais e $E$. coli, apesar de não apresentar diferença significativa ( $p>0,05)$, exceto no CT de 240 , quando apresentou diferença significativa da $E$. coli. Os resultados se mostram similares aos de Tyrrel et al. (1995), com E. coli sendo menos resistente.

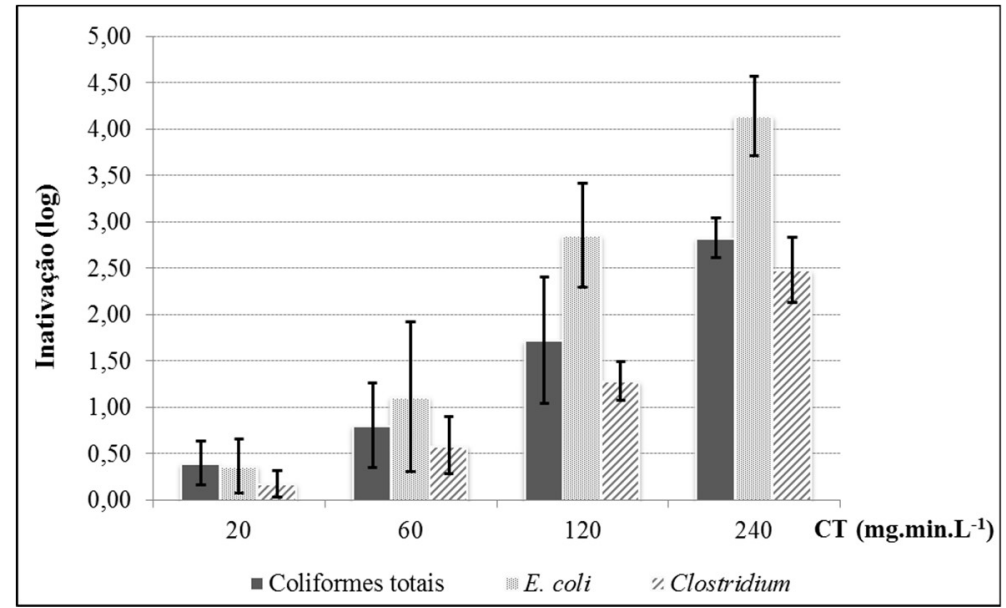

Figura 1: Resultado da inativação de micro-organismos indicadores por cloração em diferentes CTs.

Os valores médios de inativação de coliformes totais, E. coli e Clostridium sp. exibem cinética de desinfecção próxima a de Chick-Watson, com elevados valores de correlação, como é mostrada na figura 2. Este mesmo modelo de desinfecção também foi utilizado por Martínez-Hernández et al. (2013) para ensaios com hipoclorito de sódio e Zhou et al. (2017) para descrever resultados de inativação microbiana com radiação ultravioleta. Em comparação aos resultados de Medeiros e Daniel (2015a), houve menor inativação de coliformes totais e E. coli para CT próximos do presente trabalho; no entanto, maior inativação de Clostridium perfringens.

Martínez-Hernández et al. (2013), após aplicação de CT de $240 \mathrm{mg} \cdot \mathrm{min} \cdot \mathrm{L}^{-1}$, conseguiram inativar de 0,8 a 1,3 log de E. coli em efluente secundário, resultado bastante inferior ao do presente trabalho. Os 
autores sugerem possível efeito protetor promovido pelo material orgânico, com consequente decréscimo de cloro residual livre. As variações de inativação também podem estar relacionadas às diferentes características do efluente, bem como das variações de cloro residual livre e combinado durante os tempos de contato, como relatado por Medeiros et al. (2017).

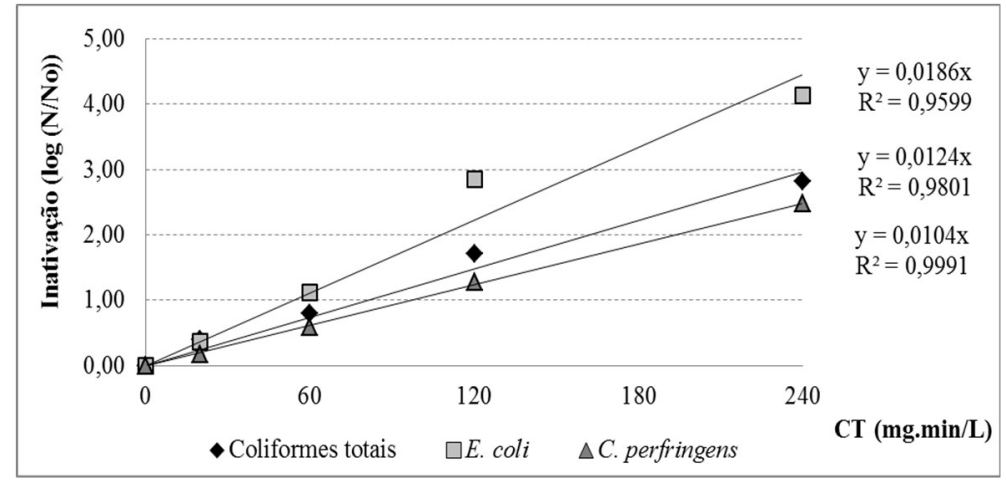

Figura 2: Cinética de desinfecção de Chick-Watson de micro-organismos indicadores durante cloração de esgoto secundário proveniente de flotador.

Os (oo)cistos de Giárdia e Cryptosporidium se mantiveram viáveis, $70 \pm 15,1 \%$ e $59 \pm 12 \%$, respectivamente, após o maior CT aplicado, não apresentando diferença significativa em relação aos outros CTs $(p>0,05)$. Medeiros et al. (2015a) também encontraram elevada resistência dos cistos de Giárdia spp. a cloração, analisada pela viabilidade com iodeto de propídeo. Assim como Rice et al. (1982), mas a partir de excistação in vitro dos cistos.

Para o trabalho, a variação das características físicas e químicas da água residuária pode ter influenciado no maior consumo de cloro livre e, consequentemente, na inativação de micro-organismos. Li et al. (2004) relataram que o cloro age primeiramente na parede do cisto resultando no aumento da permeabilidade, seguido da desintegração da membrana plasmática e de ações prejudiciais ao citoplasma, o que tornaria a célula mais vulnerável à radiação ultravioleta aplicada sequencialmente. Li et al. (2017a) citam que a desinfecção primária serve para enfraquecer as defesas celulares com pequenos danos, o que vem a ajudar a penetração na célula e ataque ao conteúdo intracelular pelo desinfetante secundário.

\section{Etapa III}

Os resultados dos três ensaios da desinfecção sequencial, na ETE - Monjolinho, podem ser visualizados na tabela 4. A discrepância entre os valores de inativação, para os ensaios I e II, pode ser devido à DQO, inferior no ensaio II (média de $77 \mathrm{mg} \cdot \mathrm{L}^{-1}$ ), apresentando inclusive concentração de CRL de 0,12 mg.L1. Enquanto que no ensaio I, a DQO foi maior (média de $115 \mathrm{mg} \cdot \mathrm{L}^{-1}$ ), consequentemente, apresentando maior consumo de cloro na oxidação da matéria orgânica e, dessa forma, restando menor concentração de CRL direcionado à desinfecção.

No ensaio III, foram aplicados $8 \mathrm{mg} \cdot \mathrm{L}^{-1}$ de hipoclorito de sódio. A DQO apresentou concentração de $22 \mathrm{mg} \cdot \mathrm{L}^{-1}$, favorecendo ainda mais a cloração, a qual apresentou inativação bastante superior, para coliformes totais e E. coli, em relação aos ensaios em bancada (etapa II), para CT próximo de $60 \mathrm{mg} \cdot \mathrm{min} \cdot \mathrm{L}^{-1}$. Após a aplicação da dosagem de $8 \mathrm{mg} \cdot \mathrm{L}^{-1}$ de cloro, foi atingida a meta microbiológica de $10^{3}$ por $\mathrm{mL}$ de $E$. coli. 
Tabela 4: Inativação (unidades logarítmicas) de microrganismos em ensaios de desinfecção sequencial na ETE Monjolinho.

\begin{tabular}{|c|c|c|c|c|c|c|}
\hline Ensaio & Micro-organismo & Cloração & UV & $\Sigma$ Inativações Individuais & Inativação Sequencial & Efeito Sinérgico \\
\hline \multirow[t]{3}{*}{1} & Coliformes totais & 0,17 & 0,41 & 0,58 & 0,25 & - \\
\hline & Escherichia coli & 0,18 & 0,21 & 0,39 & 0,49 & 0,10 \\
\hline & Clostridium sp. & 0,18 & 0,06 & 0,24 & 0,06 & - \\
\hline \multirow[t]{3}{*}{ II } & Coliformes totais & 0,66 & 0,41 & 1,07 & 0,68 & - \\
\hline & Escherichia coli & 1,09 & 0,21 & 1,30 & 0,97 & - \\
\hline & Clostridium sp. & 0,32 & 0,06 & 0,38 & 0,29 & - \\
\hline \multirow[t]{4}{*}{ III } & Coliformes totais & 3,37 & 0,52 & 3,89 & 3,67 & - \\
\hline & Escherichia coli & 3,56 & 0,23 & 3,79 & 4,08 & 0,29 \\
\hline & Clostridium sp. & 0,66 & 0,05 & 0,71 & 0,96 & 0,25 \\
\hline & Giárdia spp. & 0,05 & 0,0 & 0,05 & 0,06 & 0,01 \\
\hline
\end{tabular}

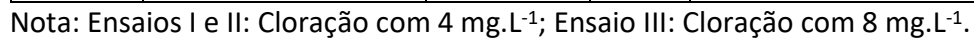

Foram encontrados efeitos sinérgicos para E. coli, Clostridium perfringens e Giárdia spp. em dois ensaios. Medeiros et al. (2015a) encontraram efeito sinérgico para desinfecção sequencial (cloração seguida de radiação ultravioleta) de esgoto tratado anaerobicamente por reator UASB, para Clostridium sp. e Giárdia spp, porém em ensaios de bancada, com CTs de cloração de 100 e 200 mg.min. L-1 . Zyara et al. (2016) também relataram efeito sinérgico na desinfecção sequencial de colifagos por cloro e radiação ultravioleta.

Montemayor et al. (2008) relatam redução de Clostridium sp. e inativação de Cryptosporidium spp. só após desinfecção sequencial por radiação ultravioleta seguida de cloração. Zhang et al. (2015), ao investigarem micro-organismos resistentes à antibióticos, encontraram efeito sinérgico de 0,06 a 0,31 log, na desinfecção de radiação ultravioleta seguida de cloração.

Li et al. (2017a; 2017b) relatam que inúmeros fatores podem afetar a desinfecção, entre eles: concentração, tempo de contato, espécies de micro-organismos, tipo de desinfetante e a qualidade do efluente. Os mesmos autores relatam efeito sinérgico com cloração em dois estágios e três estágios, devido principalmente ao tempo de contato, o qual implicaria maiores danos à parede celular e ataque intracelular, com efeito sinérgico de até 0,73 log para E. coli e diminuição da formação de subprodutos em $23 \%$. Ressaltase ainda o trabalho de Wang et al. (2011), ao avaliar que, na desinfecção sequencial, a cloração após a radiação ultravioleta, também pode ser capaz de reprimir a fotoreativação de micro-organismos.

\section{CONCLUSÕES}

Para o bom funcionamento da unidade de desinfecção por radiação UV, há necessidade de constante manutenção e limpeza das lâmpadas, além de o efluente com boa qualidade, principalmente, baixas turbidez e concentração de sólidos suspensos. Houve diferença nos resultados encontrados para cloração nos testes realizados em unidades de bancada para os testes em escala plena.

Foram verificados efeitos sinérgicos em alguns casos para E. coli, Clostridium sp. e Giárdia spp. E somente após a aplicação de $8 \mathrm{mg} \cdot \mathrm{L}^{-1}$ de cloro seguido de desinfecção por radiação UV é que foi alcançada a meta inicial de qualidade microbiológica da ETE. Deve-se atentar à presença e elevada concentração de (oo)cistos de protozoários no efluente secundário - flotado - vindo a pressionar a unidade de desinfecção em termos de bom funcionamento e eficiência de remoção e inativação. 


\section{REFERÊNCIAS}

ADAM, R. D.. Biology of Giardia lamblia. Clinical microbiology Reviews, v.14, n.3, p.447-475, 2001. DOI: http://doi.org/10.1128/CMR.14.3.447-475.2001

APHA; AWWA; WEF. Standard Methods for the Examination of Water and Wastewater. 21 ed. 2005.

BALLESTER, N. A.; MALLEY, J. P.; HIGH, L.. Sequential Disinfection of adenovirus type 2 with UV-ChlorineChloramine. Journal of American Water Works Association, v.96, n.10, p.97-103, 2004.

BITTON, G.. Wastewater Microbiology. 4 ed. New Jersey: Wiley-Blackwell. A John Wiley \& Sons, Inc., 2011.

CAMPBELL, A. T.; ROBERTSON, L.; SMITH, H.. Viability of Cryptosporidium parvum oocysts: correlation of in vitro excystation with inclusion or exclusion of fluorogenic vital dyes. Applied and Environmental Microbiology, v.58, n.11, p.3488-3493, 1992.

CANTUSIO NETO, R.; SANTOS, L. U.; FRANCO, R. M. B.. Evaluation of activated sludge treatment and the efficiency of the disinfection of Giardia species cysts and Cryptosporidium oocysts by UV at a sludge treatment plant in Campinas, south-east Brazil. Water Science and Technology, v.53, n.3, p.89-94, 2006. DOI: http://doi.org/10.2166/wst.2006.453

CAREY, C. M.; LEE, H.; TREVORS, J. T.. Biology, persistence and detection of Cryptosporidium parvum and Cryptosporidium hominis oocyst. Water Research, v.38, p.818-862, 2004. DOI: http://doi.org/10.1016/j.watres.2003.10.012

CASTRO-HERMIDA, J. A.; GARCÍA-PRESEDO, I.; ALMEIDA, A.; GONZÁLEZ-WARLETA, M.; CORREIA DA COSTA, J. M.; MEZO, M.. Contribution of treated wastewater to the contamination of recreational river áreas with Cryptosporidium spp. and Giardia duodenalis. Water Research, v.42, p.3528-3538, 2008. DOI: http://doi.org/10.1016/j.watres.2008.05.001

CETESB. Companhia de Tecnologia de Saneamento Ambiental. Método de ensaio L5.403: Clostridium perfringens - Determinação em amostras de água pela técnica de membrana filtrante (método de ensaio). CETESB, 2004.

CHÁVEZ, A.; MAYA, C.; GIBSON, R.; JIMÉNEZ, B.. The removal of microorganisms and organic micropollutants from wastewater during infiltration to aquifers after irrigation of farmland in the Tula Valley, Mexico. Environmental Pollution, v.159, p.1354-1362, 2011. DOI: http://doi.org/10.1016/j.envpol.2011.01.008

DEBORDE, M.; VON GUNTEN, U.. Reaction of chlorine with organic and inorganic compounds during water treatment Kinetics and mechanisms: A critical review. Water Research, v.42, p.13-51, 2008. DOI:

http://doi.org/10.1016/j.watres.2007.07.025

EINARSSON, E.; SVARD, S. G.; TROELL, K.. UV irradiation responses in Giardia intestinalis. Experimental Parasitology, v.154, p.25-32, 2015. DOI:

http://doi.org/10.1016/j.exppara.2015.03.024

FINCH, G. R.; LIYANAGE, L. R. J.; GYURÉK, L. L.; BRADBURY, J. S.; BELOSEVIC, M.. Synergistic Effects of Multiple Disinfectants. AWWA Research Foundation and American Water Works Association, 2000.

HIJNEN, W. A. M.; BEERENDONK, E. F.; MEDEMA, G. J.. Inactivation credit of UV radiation for viruses, bacteria and protozoan (oo)cysts in water: A review. Water Research, v.40, p.3-22, 2006. DOI:

http://doi.org/10.1016/j.watres.2005.10.030

JIN, X.; LI, Z.; XIE, L.; ZHAO, Y.; WANG, T.. Synergistic effect of ultrasonic pre-treatment combined with UV irradiation for secondary effluent disinfection. Ultrasonics Sonochemistry, v.20, p.1384-1389, 2013. DOI:

http://doi.org/10.1016/i.ultsonch.2013.03.010

LI, Y.; SMITH, D. W.; BELOSEVIC, M.. Morphological changes of Giardia lamblia cysts after treatment with ozone and chlorine. Journal of Environmental Engineering and Science, v.3, p.495-506, 2004. DOI: http://doi.org/10.1139/s04011

LI, Y.; YANG, M.; ZHANG, X.; JIANG, J.; LIU, J.; YAU, C. F.; GRAHAM, N. J. D.; LI, X.. Two-step chlorination: a new approach to disinfection of a primary sewage effluent. Water Research, v.108, p.339-347, 2017a. DOI: http://doi.org/10.1016/i.watres.2016.11.019

LI, Y.; ZHANG, X.; YANG, M.; LIU, J.; LI, W.; GRAHAM, N. J. D.; $\mathrm{LI}, \mathrm{X}$; Y YANG, B.. Tree-step effluent chlorination increases disinfection efficiency and reduces DBP formation and toxicity. Chemosphere, v.168, p.1302-1308, 2017b. DOI: http://doi.org/10.1016/i.chemosphere.2016.11.137

MARTÍNEZ-HERNÁNDEZ, S.; VÁZQUEZ-RODRÍGUEZ, G. A.; BELTRÁN-HERNÁNDEZ, R. I.; PRIETO-GARCÍA, F.; MIRANDALOPEZ, J. M.; FRANCO-ABUÍN, C. M.; ÁLVAREZ-HERNÁNDEZ, A.; ITURBE, U.; CORONEL-OLIVARES, C.. Resistance and inactivation kinetics of bacterial strains isolated from the non-chlorinated and chlorinated effluents of a WWTP. International Journal of Environmental Research and Public Health, v.10, p.3363-3383, 2013. DOI:

http://doi.org/10.3390/ijerph10083363

MEDEIROS, R. C.; DANIEL, L. A.. Study of sequential disinfection for the inactivation of protozoa and indicator microorganisms in wastewater. Acta

Scientiarum.Technology, Maringá, v.37, n.2, p.203-209, 2015a. DOI:

http://doi.org/10.4025/actascitechnol.v37i2.24950

MEDEIROS, R. C.; DANIEL, L. A.. Comparison of selected mehods for recovery of Giardia spp. cysts and Cryptosporidium spp. oocysts in wastewater. Journal of Water and Health, v.13, n.3, p.811-818, 2015b. DOI: http://doi.org/10.2166/wh.2015.228

MEDEIROS, R. C.; DANIEL, L. A.. Cloração de esgoto sanitário: variação de cloro residual e o uso de parâmetros facilmente mensuráveis na indicação de breakpoint. Revista DAE, v.206, p.87-98, 2017. DOI: http://doi.org/10.4322/dae.2016.030 
MONTEMAYOR, M. COSTAN, A.; LUCENA, F.; JOFRE, J.; MUNOZ, J.; DALMAU, E.; MUJERIEGO, R.; SALA, L.. The combined performance of UV light and chlorine during reclaimed water disinfection. Water Science and Technology, v.57, n.6, p.935-940, 2008. DOI: http://doi.org/10.2166/wst.2008.206

MOULIN, L.; RICHARD, F.; STEFANIA, S.; GOULET, M.; GOSSELIN, S.; GONÇALVES, A.; ROCHER, V.; PAFFONI, C.; DUMÈTRE, A.. Contribution of treated wastewater to the microbiological quality of Seine River in Paris. Water Research, v.44, p.5222-5231, 2010. DOI: http://doi.org/10.1016/j.watres.2010.06.037

NADDEO, V.; LANDI, M.; BELGIORNO, V.; NAPOLI, R. M.. Wastewater disinfection by combination of ultrasound and ultraviolet irradiation. Journal of Hazardous Materials, v.168, p.925-929, 2009. DOI:

http://doi.org/10.1016/j.jhazmat.2009.02.128

PARK, K.; CHOI, S.; LEE, S.; KWEON, J.; SONG, J.. Comparison of formation of disinfection by-products by chlorination and ozonation of wastewater effluents and their toxicity to Daphnia magna. Environmental Pollution, v.215, p.314-321, 2016. DOI: http://doi.org/10.1016/j.envpol.2016.04.001

RICE, E. W.; HOFF, J. C.; SHAEFFER III, F. W.. Inactivation of Giardia cysts by chlorine. Applied Environmental Microbiology, v.43, n.1, p.250-251, 1982.

ROBERTSON, L. J.; PATON, C. A.; CAMPBELL, A. T.; SMITH, P. G.; JACKSON, M. H.; GILMOUR, R. A.; BLACK, S. E.; STEVENSON, D. A.; SMITH, H. V.. Giardia cysts and Cryptosporidium oocysts at sewage treatment works in Scotland, UK. Water Research, v.34, n.8, p.2310-2322, 2000. DOI: http://doi.org/10.1016/S0043-1354(99)00408-X

SANCTIS, M.; MORO, G. D.; LEVANTESI, C.; LUPRANO, M. L.; DI IACONI, C. Integration of an innovative biological treatment with physical or chemical disinfection for wastewater reuse. Science of the Total Environment, v.543, p.206-213, 2016. DOI:

http://doi.org/10.1016/i.scitotenv.2015.11.006

SANTOS, P. R.; DANIEL, L. A.. Occurrence and removal of Giardia spp. cysts and Cryptosporidium spp. oocysts from a municipal wastewater treatment plant in Brazil.
Environmental Technology, v.38, n.10, p.1245-1254, 2017. DOI: http://doi.org/10.1080/09593330.2016.1223175

SEDLAK, D. L.; VON GUNTEN, U.. The chlorine dilemma.

Science, v.331, p.42-43, 2011. DOI:

http://doi.org/10.1126/science.1196397

TONANI, K. A. A.; PADULA, J. A.; JULIÃO, F. C.; FREGONESI, B. M.; ALVES, R. I. S.; SAMPAIO, C. F.; BEDA, C. F.; HACHICH, E. M.; SEGURA-MUNOZ, S. I.. Persistence of Giardia, Cryptosporidium, Rotavirus and Adenovirus in treated sewage in São Paulo State, Brazil. Journal of Parasitology, v.99, n.6, p.1144-1147, 2013. DOI: http://doi.org/10.1645/12-121.1

TYRREL, S. A.; RIPPEY, S. R.; WATKINS, W. D.. Inactivation of bacterial and viral indicators in secondary sewage effluents, using chorine and ozone. Water Research, v.29, n.11, p.2483-2490, 1995.

WANG, X.; HU, X.; HU, C.; WEI, D.. Sequential use of ultraviolet light and chlorine for reclaimed water disinfection. Journal of Environmental Sciences, v.23, n.10, p.1605-1610, 2011.

WANG, X.; HU, X.; WANG, H.; HU, C.. Synergistic effect of the sequential use of UV irradiation and chlorine to disinfect reclaimed water. Water Research, v.46, p.1225-1232, 2012. DOI: http://doi.org/10.1016/i.watres.2011.12.027

ZHANG, Y.; ZHUANG, Y.; GENG, J.; REN, H.; ZHANG, Y.; DING, $\mathrm{L}$.; $\mathrm{XU}, \mathrm{K}$.. Inactivation of antibiotic resistence genes in municipal wastewater effluent by chlorination and sequential UV/chlorination disinfection. Science of the Total Environment, v.512-513, p.125-132, 2015. DOI: http://doi.org/10.1016/j.scitotenv.2015.01.028

ZHOU, X.; LI, Z.; LAN, J.; YAN, Y.; ZHU, N.. Kinetics of inactivation and photoreactivation of Escherichia coli using ultrasound-enhanced UV-C light-emitting diodes disinfection. Ultrasonics Sonochemistry, v.35, p.471-477, 2017. DOI: http://doi.org/10.1016/i.ultsonch.2016.10.028

ZYARA, A. M.; TORVINEN, E.; VEIJALAINEN, A.; HEINONENTANSKI, H.. The effect of UV and combined chlorine/UV treatment on coliphages in drinking water disinfection. Water, v.130, p.1-9, 2016. DOI: http://doi.org/10.2166/wh.2016.144

A CBPC - Companhia Brasileira de Produção Científica (CNPJ: 11.221.422/0001-03) detém os direitos materiais desta publicação. Os direitos referem-se à publicação do trabalho em qualquer parte do mundo, incluindo os direitos às renovações, expansões e disseminações da contribuição, bem como outros direitos subsidiários. Todos os trabalhos publicados eletronicamente poderão posteriormente ser publicados em coletâneas impressas sob coordenação da Sustenere Publishing, da Companhia Brasileira de Produção Científica e seus parceiros autorizados. Os (as) autores (as) preservam os direitos autorais, mas não têm permissão para a publicação da contribuição em outro meio, impresso ou digital, em português ou em tradução. 